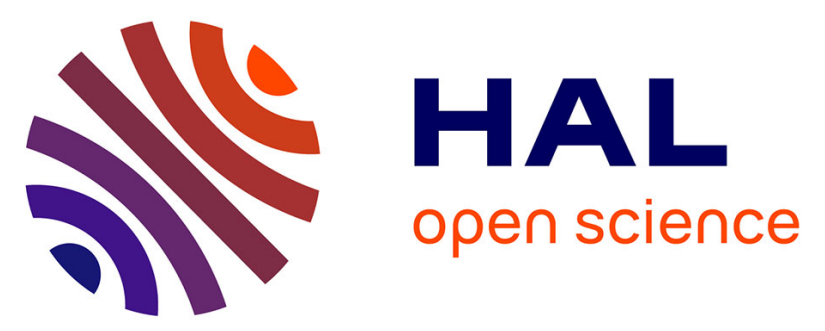

\title{
Higher education in a material world: Constraints to digital innovation in Portuguese universities and polytechnic institutes
}

Paulo Nuno Vicente, Paulo Nuno Vicente, Margarida Lucas, Vânia Carlos, Pedro Bem-Haja

\section{To cite this version:}

Paulo Nuno Vicente, Paulo Nuno Vicente, Margarida Lucas, Vânia Carlos, Pedro Bem-Haja. Higher education in a material world: Constraints to digital innovation in Portuguese universities and polytechnic institutes. Education and Information Technologies, 2020, 25, pp.5815 - 5833. 10.1007/s10639-020-10258-5 . hprints-03201115

HAL Id: hprints-03201115

https://hal-hprints.archives-ouvertes.fr/hprints-03201115

Submitted on 17 Apr 2021

HAL is a multi-disciplinary open access archive for the deposit and dissemination of scientific research documents, whether they are published or not. The documents may come from teaching and research institutions in France or abroad, or from public or private research centers.
L'archive ouverte pluridisciplinaire HAL, est destinée au dépôt et à la diffusion de documents scientifiques de niveau recherche, publiés ou non, émanant des établissements d'enseignement et de recherche français ou étrangers, des laboratoires publics ou privés. 


\title{
Higher education in a material world: Constraints to digital innovation in Portuguese universities and polytechnic institutes
}

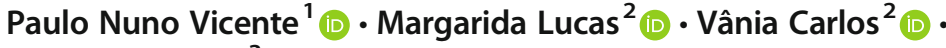 \\ Pedro Bem-Haja ${ }^{3}$ (iD
}

Received: 26 May 2020 / Accepted: 17 June 2020/Published online: 20 June 2020

(C) Springer Science+Business Media, LLC, part of Springer Nature 2020

\begin{abstract}
Over the past decade, the societal impact of digital transformation, with the prospects of a Fourth Industrial Revolution, has led to an innovation imperative in European policymaking regarding higher education institutions (HEIs). However, not only is the institutional strategic planning of HEIs still understudied, as the individual perceptions of faculty members about existing constraints to digital innovation have been particularly overlooked. This article examines Portuguese universities and polytechnic institutes, the two components of the national higher education system, to (1) characterize the quality of the available digital infrastructure and resources (hardware and software) and (2) identify the main constraints to digital innovation. The study conducts the most comprehensive online questionnaire available to date on these topics across Portuguese HEIs $(N=547)$. The main constraints to digital innovation correspond to limited infrastructure and resources, lack of funding opportunities, insufficient technological resources, a conservative academic culture, and a lack of technical support. These barriers impact Portuguese regional development, as discussed in this study, highlighting the need for the modernization of HEIs.
\end{abstract}

Keywords Digital innovation · Higher education · Digital infrastructure · Portugal · Regional development

Paulo Nuno Vicente

inovamedialab@fcsh.unl.pt

1 iNOVA Media Lab/ICNOVA, Universidade Nova de Lisboa, Lisbon, Portugal

2 Universidade de Aveiro CIDTFF, Aveiro, Portugal

3 Universidade de Aveiro, CINTESIS, Aveiro, Portugal 


\section{Introduction}

Higher education institutions (HEIs) have long been identified as key agents for innovation and national and regional development (Caniëls and van den Bosch 2010; European Commission 2014; Brennan et al. 2018). In Europe, this role has faced considerable challenges over past decades as a result of different policy frameworks (e.g., the Bologna Process) and societal demands (e.g., digitization, fast-changing employment landscape). Different studies and recommendations on innovation in higher education (HE) stress that successful innovative practices are the result of multiple interconnected factors operating at national/regional and institutional levels, such as institutional autonomy, an overarching vision matched by strategy, and an expenditure on research and development $(R \& D)$ or existing infrastructure (Brennan et al. 2018; European Commission 2014; Marshall 2018a; Reichert 2019). The latter is highlighted as a facilitator of networks among third parties, supported governance, and innovative pedagogical practices (Altbach 2016; Brennan et al. 2014; European Commission 2018; Serdyukov 2017; Veletsianos 2016).

Portugal has been active in following European recommendations for the digitization of education, but efforts often emanate from individual HEIs rather than from policymaking (Dias and Gomes 2018). The call to implement a "Bologna Digital" (Rampelt et al. 2018) and a Digital Education Action Plan (European Commission 2018) pressures HEIs to focus on different action lines. At the same time, HEIs are faced with considerable constraints that may prevent actions from being taken and transformation from being achieved. These include financial and funding constraints; lack of digital infrastructure, resources, and technical support; supportive institutional governance; or individual attitudes toward digital technologies (Ávila et al. 2017; Kezar and Eckel 2002; Kezar 2018; Lašáková et al. 2017; Marshall 2018a; Posselt et al. 2018).

The study of innovation in HEIs and the role of technological change have been the object of different studies (e.g. Fox 2011; Kraft 1971; Luehrmann 1989; Razik and Nalbone 1990; Smertenko et al. 2018). Nevertheless, institutional strategic planning and policy related to digital innovation in HEIs are still under-researched domains (Bond et al. 2018). In addition, research has been focusing on macro factor levels, leaving a gap in terms of individuals and their perceptions of constraints to innovation within their own institution. In this respect, as digital media and the technologies associated with the Internet become pervasive in contemporary HE contexts, clear and precise knowledge of the direct experiences of faculty members with digital infrastructure and equipment is key.

The present study aims to characterize the self-reported quality of the available digital infrastructure and equipment (software and hardware) and to identify key constraints to innovation across Portuguese HEIs. The study intends to provide the research community and policy makers with a comprehensive study that maps results against regions and HE subsystems.

\section{Constraints to innovation in HEls}

Innovation can be broadly defined as the creation or improvement of ideas, products, processes, services, or methods to advance activities of an HE institution or its regional 
context (Brennan et al. 2014; Hasanefendic et al. 2017). At a regional level, innovation driven by HEIs involves different dimensions (Caniëls and van den Bosch 2010; Reichert 2019). One is to contribute to the human capital and skills development, not only of students, but also of employees. Another is to develop locally relevant R\&D activities, and still another is to exchange knowledge by engaging with external stakeholders. All these are linked to a core dimension, which involves the strategic transformation of institutional processes. One transversal facet of all dimensions is technology, particularly digital technology (Brennan et al. 2014; Marshall 2018b; Posselt et al. 2018).

Although the availability of technological and physical resources is only one of the factors shaping change in HE, on their own, they do mold the exchange and dissemination of knowledge (Moodie 2016). Digital information and communication technologies have a direct impact, not only on conceptions of learning and teaching, but also on how these are organized, managed, and technically supported (e.g., Rosario 2012; Shoham and Perry 2009; Välimaa and Hoffman 2008).

Based on evidence collected across 10 European universities, a recent study on the barriers and drivers of innovation in HE found three major clusters of hurdles: external macro-level barriers of innovation, internal barriers acting within the participants' organizational environment, and individual-level barriers (Lašáková et al. 2017). At the external macro level, the major barriers identified corresponded to rigid rules and inflexible administration, Information and Communication Technologies' (ICT) insufficiencies, and weak interplay with businesses. At the institutional level, the main barriers identified related to the lack of a vision and inconsistent strategies, as well as rigid human resource management operations. At the individual level, barriers referred mostly to unprepared and disengaged faculty members, both in terms of ICT skills and innovative ways of teaching.

These results are in line with those identified by other studies focusing on innovation and HEIs (Ávila et al. 2017; Blaschke et al. 2014; Brennan et al. 2014). Others point at further barriers. For instance, Marshall (2018a) focuses on the financial challenges and funding constraints HEIs face in relation to the increasing cost of education and concomitant decreases in public investment. Kezar (2018) looks at the organizational culture and its effects on change strategies, while Harrison and Hargrove (2006) and Paganelli and Cangemi (2019) concentrate on aging faculty and its influence on institutional policies and practices. In this specific regard, Hasanefendic et al. (2017) stress the importance of individuals' motivation and interest in driving disruptive and transformative approaches. In addition, at the individual level, García and Roblin (2008) highlight the importance of dialogue and collaboration among teachers and students.

The study of digital innovation in Portuguese HEIs is a fairly novel topic. Different studies have focused on internalization, economic impacts, or mismatches between expected skills and the current needs of the labor market (Alves et al. 2015; Fernandes et al. 2013; Figueiredo et al. 2017; Mesquita and Castilho 2017), but little is known about the existing constraints to digital innovation. Therefore, examining perceptions on the topic among faculty members of Portuguese HEIs is of crucial interest.

\subsection{The Portuguese context}

Portuguese higher education is organized into two subsystems (universities and polytechnic institutions), featuring the coexistence of both public and private sectors. In 
general, universities are guided by a perspective of research promotion and creation of knowledge, and they aim at ensuring solid scientific training, while polytechnics are guided by a perspective of applied R\&D, and they aim at providing vocational and advanced technical training for the labor market (Flores et al. 2019; Kauko and Diogo 2012; OECD 2019). The Portuguese HE subsystems were shaped by the adoption of the Bologna Declaration in 1999, which resulted in a wider alignment with European Higher Education Area (EHEA) principle goals in mobility, employability, quality assurance, and the development of lifelong learning (EHEA 1999). New roles were established regarding HEIs and their role in creating, sharing, and exploiting knowledge of direct benefit to the wider economy and society around them (OECD 2019).

There are currently 287 HEIs in Portugal (Table 1). The majority is concentrated in the North, Center, and Lisbon regions, following the national urban landscape. Universities are also mostly based in the major cities located in these regions, while polytechnics are more spread throughout the country (Direção Geral do Ensino Superior (DGES) 2018). This was part of a national policy to strengthen territorial cohesion and promote regional development in areas with no universities or with a low level of development, such as the interior areas of Portugal (File 2008; Governo da República Portuguesa 2017). The lowest number of HEIs can be found in the Autonomous Regions of the Azores (Azores AR) and Madeira (Madeira AR). These regions are also the smallest in terms of territorial area.

Current data on funding awarded for R\&D activities demonstrate that Lisbon is the largest beneficiary and Madeira AR the smallest (Direção Geral do Ensino Superior (DGES) 2017). The Center and North regions follow as major beneficiaries, and the difference between funding awarded to these regions and that awarded to the remaining ones is striking. Nevertheless, Portugal is committed to increasing its level of R\&D investment in less developed regions by 2030 (Direção Geral do Ensino Superior (DGES) 2018). Similar commitments are assumed in relation to the alignment of the profiles and missions of HEIs to meet national and regional needs, the stimulation of knowledge and innovation, and the improvement of HEIs' digitization, combined with

Table 1 Number of HEIs by NUTS II (PORDATA 2019)

\begin{tabular}{llll}
\hline NUTS II & Subsystems & & \\
\cline { 2 - 4 } & Total & University & Polytechnic \\
\hline Portugal & 287 & 123 & 164 \\
North & 99 & 40 & 59 \\
Center & 53 & 16 & 37 \\
Lisbon & 89 & 50 & 39 \\
Alentejo & 19 & 4 & 15 \\
Algarve & 11 & 5 & 6 \\
Azores AR & 8 & 4 & 4 \\
Madeira AR & 8 & 4 & 4 \\
\hline
\end{tabular}

Portugal is divided into seven different NUTS II (Nomenclature of Territorial Units for Statistics), corresponding to the "regions": North; Center; Lisbon Metropolitan Area (Lisbon); Alentejo; Algarve; Autonomous Region of the Azores (Azores AR); Autonomous Region of Madeira (Madeira AR) 
internet access and usage (Direção Geral do Ensino Superior (DGES) 2018; OECD 2019).

In terms of regional digital indexes (RDIs), data point at an increased level of digitization among all Nomenclature of Territorial Units for Statistics II (NUTS II) regions between 2017 and 2018 (Ferreira and Amaral 2019). The exception refers to the Alentejo region, which distances itself from the average calculated for Portugal. Thus, Lisbon maintains its top position, scoring significantly higher than any other region. Considering the latest four RDI sub-indexes, territorial disparities can be found at different levels: (i) Context: conditions for the development of a digital society are more favorable in Lisbon, while conditions in other regions have been worsening due to the asymmetries between Portuguese regions; (ii) Infrastructure: the Algarve is the only region, apart from Lisbon, to score above the national average. This contrasts with the downward trend of all other regions, which are already below the national average; (iii) Use: only the Algarve region matches Lisbon in performance scoring above the national average. All the other regions score below the national average; (iv) Impact: only Lisbon scores above the national average, which reinforces the notion of regional asymmetries.

Such a panorama compromises national cohesion, commitments undertaken, and the provision of equal opportunities to Portuguese citizens. Moreover, it highlights that knowing the territory at the NUTS II level is, in fact, crucial for the definition of public policies capable of countering this trend of worsening regional asymmetries (Ferreira and Amaral 2019). Further data to complement and better depict a national overview regarding conditions for HEIs to drive digital innovation is needed. The aim of the present study is to characterize the quality of the available digital infrastructure and resources in Portuguese HEIs and to identify the main constraints to digital innovation as perceived by faculty members of HEIs. To this end, the perceptions of faculty members were analyzed in terms of regional location (NUTS II) and HE subsystem using the following research questions (RQ):

RQ1. What are faculty members' perceptions of the quality of the available digital infrastructure?

RQ2. What are faculty members' perceptions of the quality of the available resources (hardware and software)?

RQ3. Which are the main constraints to digital innovation identified by faculty members?

\section{Research methods}

\subsection{The online questionnaire}

For data collection, an online questionnaire was designed using the Qualtrics Survey web-based platform, containing seven sections: (i) socio-demographic composition, (ii) infrastructure and resources, (iii) digital skills for teaching, (iv) mobility and professional experience, (v) teaching environment, (vi) knowledge of the European digital innovation agenda, and (vii) constraints to innovation. Sections (i), (ii), and (vii) were used to answer the specific research questions of this article. Section (i) was used to establish background information about the respondents, section (ii) to characterize the 
quality of the available digital infrastructure and resources (hardware and software), and section (vii) to identify the main constraints to digital innovation. Section (ii) was measured by two questions using a scale ranging from "Totally disagree" (1) to "Totally agree" (5) and section (vii) by employing a drill-down question type.

The online questionnaire was pretested with a group of 11 HEI faculty members. This sample of potential respondents assessed any needs for revision and improvement in the survey design. The main objective was to check wording, technical jargon and conceptual clarity, spell checking, and navigation structure. According to the pilot group feedback, minor adjustments were implemented to optimize the comprehension and readability of the instructions (e.g., normalization of expressions in Portuguese), as well as the questionnaire's digital user experience (e.g., introduction of a backspace button). After operationalizing these adjustments, the definite data collection instrument was created. The internal consistency of the questionnaire was assessed by Cronbach's alpha (.822).

\subsection{Sample and procedure}

In total, 642 responses were collected. Of these, 95 respondents (14.8\%) did not answer all questions and were, therefore, excluded. As such, our study sample was made of 547 faculty members. The demographic data of the sample are presented in Table 2.

The target participants for our study were faculty members engaged in teaching in Portuguese HEIs distributed by the dual system composed of universities and polytechnic institutes across the public and the private sectors and in all scientific domains and Portuguese regions. We prepared for this study by composing a maximum variation/heterogeneous purposive sample based on the fundamental inclusion condition of being publicly identified as a faculty member on the institutional web page (e.g., department, college, school) of a Portuguese HEI, covering all officially registered universities and polytechnic institutes across the public and the private sectors and in all scientific domains and Portuguese regions. Using this exploratory sampling criteria, a database with 8563 entries was composed.

Participants were individually contacted via the institutional email made publicly available on their educational institution website. Informed consent was obtained by explicitly explaining the research objectives, the intervenient researchers and their institutions, and the terms of the applicable privacy and anonymity regulations both in the email body and in the questionnaire header. The online questionnaire was released on May 3, 2019, only accessible by direct link, and distributed amongst the sample database. Individual reminders were sent weekly, totalling three. The questionnaire was closed on May 30, 2019.

\subsection{Data analysis}

To answer RQ1 and RQ2, two two-way analyses of variance (ANOVAS) were used, with a top-down approach, and the Bonferroni correction was used in multiple comparisons. Structurally, the two two-way ANOVAS were made up of two factors: "HE subsystems" with two levels (University and Polytechnic) and "NUTS II regions" with seven levels (Alentejo, Algarve, Center, Lisbon, North, Madeira AR and Azores AR). 
Table 2 Demographic characteristics of the respondents

\begin{tabular}{|c|c|c|c|c|c|c|c|}
\hline Gender & Male & Female & Other & & & & \\
\hline $\mathrm{N}$ & 259 & 286 & 2 & & & & \\
\hline$\%$ & 52.3 & 47.4 & 0.3 & & & & \\
\hline Age (M) & \multicolumn{7}{|c|}{$40.2(\mathrm{SD}=9.2)$} \\
\hline $\begin{array}{l}\text { Teaching experience } \\
\text { (M) }\end{array}$ & \multicolumn{3}{|c|}{$18.9(\mathrm{SD}=10.3)$} & & & & \\
\hline HEI subsystem & University & Polytechnic & Both & & & & \\
\hline $\mathrm{N}$ & 268 & 246 & 33 & & & & \\
\hline$\%$ & 49 & 45 & 6 & & & & \\
\hline Age (M) & $\begin{array}{l}51.8 \\
(\mathrm{SD}=9.39)\end{array}$ & $\begin{array}{l}49.7 \\
(\mathrm{SD}=8.28)\end{array}$ & $\begin{array}{l}51.7 \\
(\mathrm{SD}=12.6)\end{array}$ & & & & \\
\hline $\begin{array}{l}\text { Teaching experience } \\
\text { (M) }\end{array}$ & $\begin{array}{l}20.6 \\
(\mathrm{SD}=10.9)\end{array}$ & $\begin{array}{l}17.1 \\
(\mathrm{SD}=9.3)\end{array}$ & $\begin{array}{l}19.4 \\
(\mathrm{SD}=10.7)\end{array}$ & & & & \\
\hline Sector & Public & Private & & & & & \\
\hline $\mathrm{N}$ & 443 & 104 & & & & & \\
\hline$\%$ & 81 & 19 & & & & & \\
\hline NUTS II & North & Center & Lisbon & Alentejo & Algarve & $\begin{array}{c}\text { Azores } \\
\text { AR }\end{array}$ & $\begin{array}{c}\text { Madeira } \\
\text { AR }\end{array}$ \\
\hline $\mathrm{N}$ & 163 & 113 & 145 & 44 & 36 & 30 & 16 \\
\hline$\%$ & 29.8 & 20.7 & 26.5 & 8 & 6.6 & 5.5 & 2.9 \\
\hline
\end{tabular}

To answer RQ3, a Chi-square was performed to analyze the absolute differences in proportions inferentially.

\section{Results}

The results are arranged in three parts, each corresponding to a research question.

\subsection{Perceptions of faculty members regarding the quality of available digital infrastructure}

Regarding the perceived quality of digital infrastructures, the mean scores obtained by HE subsystems (university and polytechnic) and NUTS II regions (Alentejo, Algarve, Center, Lisbon, North, Madeira AR and Azores AR and Azores AR) are shown in Fig. 1.

It is possible to verify the homogeneity of perceived quality across regions. The exception is found in relation to the Azores AR, which registers values of perceived quality well below those registered in other regions. No major fluctuation is verified in the perceived quality of digital infrastructure across HE subsystems. Nevertheless, scores obtained by each HE subsystem vary according to NUTS II. For instance, while in the Alentejo and Algarve regions the perception of digital infrastructure quality is better among university faculty members, in the Center, the difference is subtle, but 


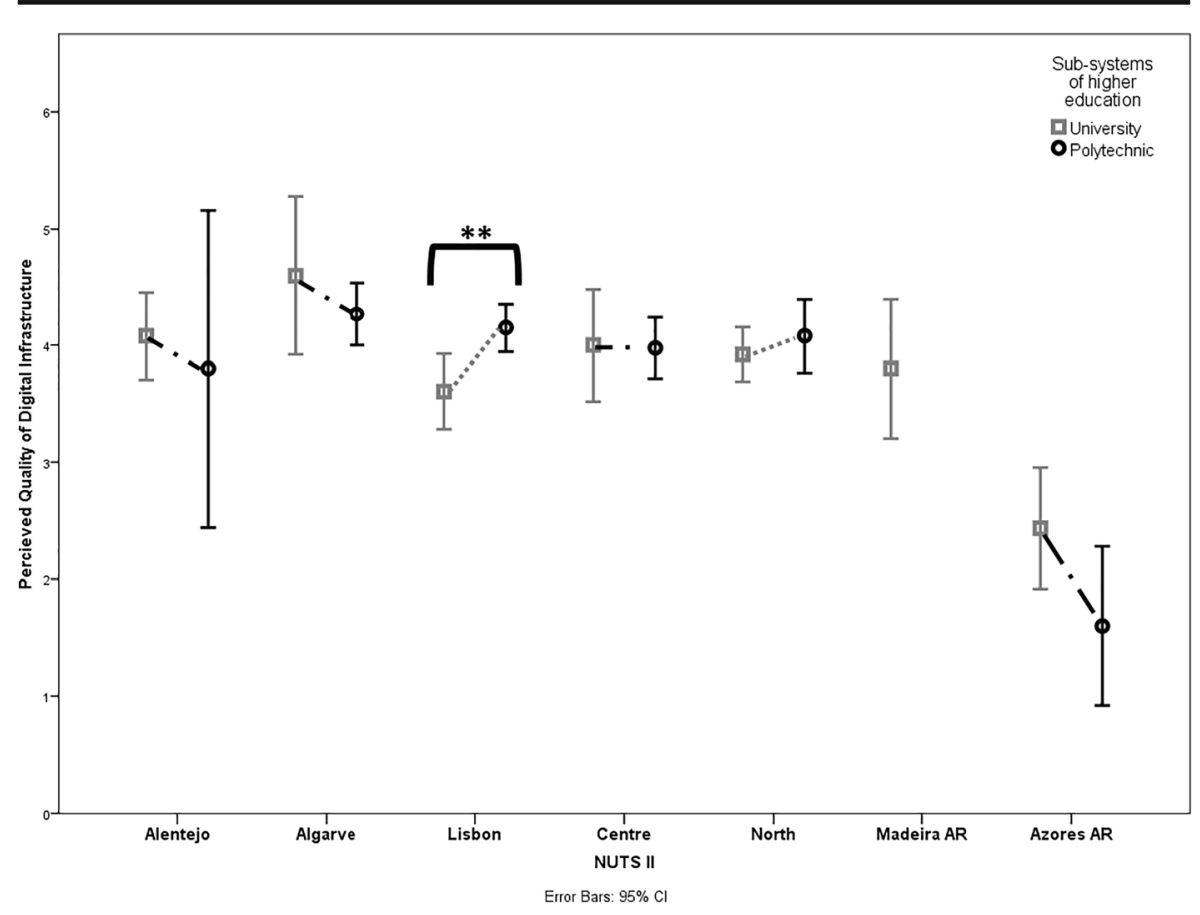

Fig. 1 Mean scores of the perceived quality of infrastructures by HE subsystem and NUTS II region

also favoring universities. On the contrary, in the North and Lisbon regions, the quality of the digital infrastructure is better perceived by faculty members from the polytechnic system. As there were no answers from the polytechnic system in the Madeira AR, it is not possible to compare perceptions among faculty members from both $\mathrm{HE}$ subsystems.

To establish the pattern described above inferentially and to test whether the verified differences would reach statistical significance, a full between two factors (university and polytechnic) and *seven levels (Alentejo, Algarve Lisbon, Center, North, and Azores AR) ANOVA was performed. The ANOVA showed a main effect of NUTS II $\left(F[6500]=10.887, p<.001, \eta_{p}{ }^{2}=.095\right)$ and a statistical trend of interaction $\left(F[5500]=2.330, p=.09, \eta_{p}^{2}=.018\right)$, but no effect of HE subsystem $\left(F[5500]=.575, p=.449, \eta_{p}^{2}=.001\right)$ was found.

Considering the NUTS II effect, multiple comparisons were made with a Bonferroni correction. The results of the multiple comparisons showed statistically significant differences only between the Azores AR and all the other regions ( $p$ 's $<.001$ for all comparisons). To explore better the interactive trend between NUTS II and HE subsystems, multiple comparisons were also performed. The results of these analyses showed that despite the absolute differences illustrated by Fig. 1, the perceived quality of digital infrastructures only differs between university and polytechnic in Lisbon $(t[136]=-3.13, p<.001,95 \% C I[-0.90,-0.19]$, Hedges' $g s=0.54)$. The Common Language effect size indicates that when we select a pair of individuals randomly (one from the Polytechnic, the other from the University), the probability of the individual from the Polytechnic individual to score higher than the University individual is $65 \%$. 


\subsection{Perceptions of faculty members regarding the quality of the available resources}

Concerning the perceived quality of resources (hardware and software), the mean scores obtained by HE subsystems (University and Polytechnic) and NUTS II regions (Alentejo, Algarve, Center, Lisbon, North, Madeira AR and Azores AR) are shown in Fig. 2. Similar to the previous analysis, the results obtained in the various NUTS II regions do not vary widely, except for the Azores AR. Moreover, the values of the perceived quality of the resources do not vary much across HE subsystems, but their relationship varies according to NUTS II region. In the Alentejo, Lisbon, Center, and North regions, the perception of the quality of resources is better among faculty members from the Polytechnic institution, whereas in the Algarve and Azores regions, this perception is better among faculty members from the University. Again, as there were no answers from the Polytechnic system in the Madeira AR, it is not possible to compare perceptions of faculty members from both HE subsystems.

A full between two factors (Polytechnic and University) and *seven levels (Alentejo, Algarve Lisbon, Center, North, Madeira AR, and Azores AR) ANOVA was performed to validate the descriptive results inferentially. The ANOVA showed a main effect of NUTS II $\left(F[6499]=5.811, p<.001, \eta_{p}{ }^{2}=.065\right)$, but no effect of HE subsystem $\left(F[5500]=.691, p=.406, \eta_{p}^{2}=.001\right)$ or interaction $\left(F[5500]=.727, p=.623, \eta_{p}{ }^{2}=\right.$ 007) was found. Considering the NUTS II effect, multiple comparisons were made with Bonferroni correction. In this case, the results of the multiple comparisons also showed significant differences between the Azores AR and all other regions $(p$ 's $<.001$ for all comparisons). No other significant results were obtained.

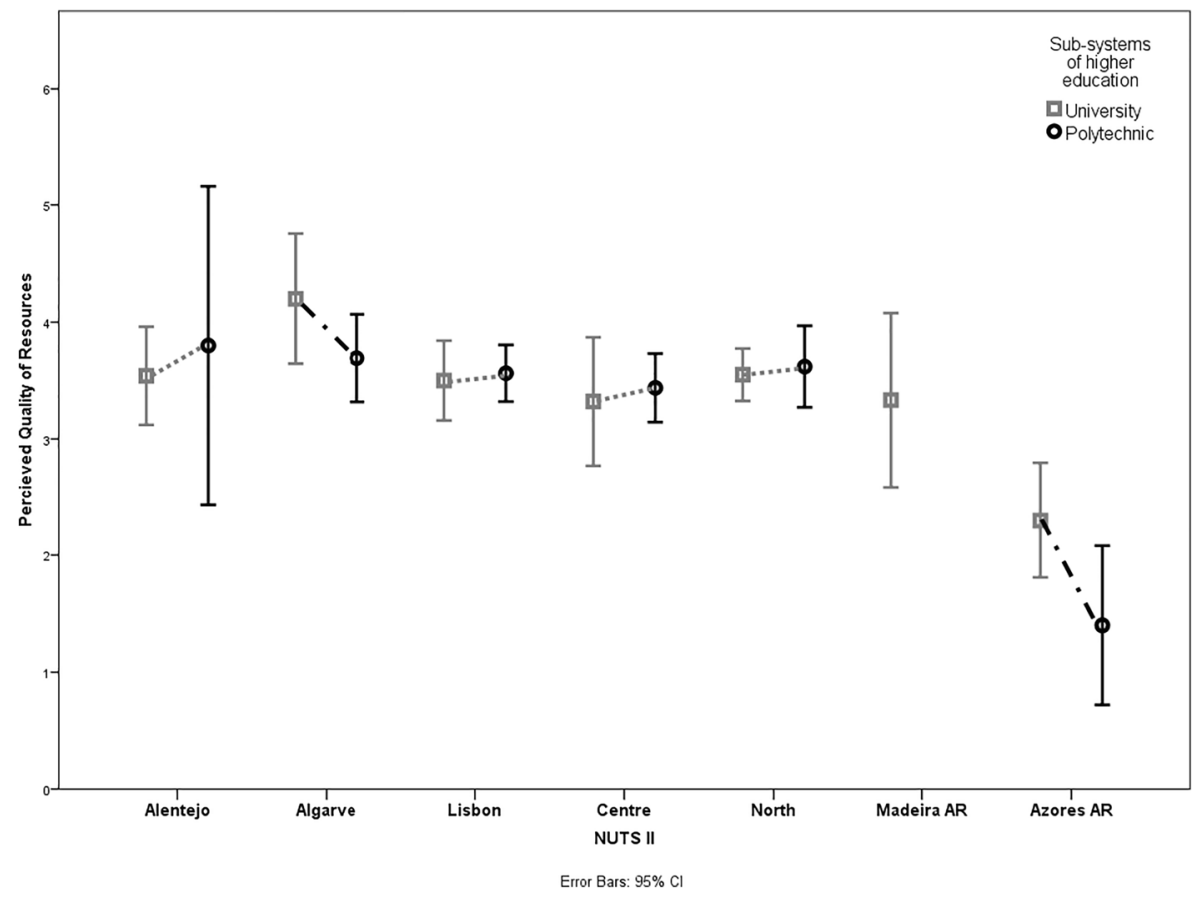

Fig. 2 Mean scores of the perceived quality of resources by HE subsystem and NUTS II region 


\subsection{Main constraints to digital innovation}

To verify whether the constraints to digital innovation differed in terms of HE subsystems and NUTS II region, the descriptive differences regarding the proportion of individuals choosing each of the constraints were explored (Table 3). The strongest differences are highlighted and marked in bold font. Those signaled with asterisks correspond to statistically significant differences.

Regarding the Alentejo region, the proportion of respondents who selected the "Aging faculty" option as a constraint to digital innovation was greater among faculty members from the University subsystem, but the difference was not significant. However, the proportion of participants who selected "Rigid and inflexible rules" $(\chi 2=11.8, p<.001)$ and "Inappropriate administrative organization" $(\chi 2=9.02$, $p<.01)$ as constraints was significantly greater among faculty members from the Polytechnic institution than from the University.

With regard to the Algarve, while the proportion of respondents from the Polytechnic subsystem who selected the "Lack of collaboration among peers" and the "Lack of technological resources" as the main constraints to digital innovation was greater, the proportion of respondents from the University subsystem who selected the "Limited infrastructure and resources" was greater. Despite these absolute differences, none achieved statistical significance.

Relative to the Lisbon region, there were more respondents from the University subsystem choosing the "Aging faculty" and "Conservative academic culture" options, but more respondents from the Polytechnic subsystem opting for the "Limited infrastructure and resources" constraint. However, and despite the absolute differences achieved, statistical significance was only found for the "Aging faculty" constraint $(\chi 2=6.07, p=.014)$.

For the Center region, the proportion was higher among faculty members from the University subsystem regarding the options "Lack of technical support" and "Limited infrastructure and resources," and it was higher among faculty members from the Polytechnic regarding the "Lack of technological resources" option. Differences found were, but they were not significant.

Concerning the North region, the proportion of respondents who selected the "Lack of technical support" and "Lack of technological resources" options as constraints to digital innovation was greater within the Polytechnic subsystem. Contrary to this, the proportion of respondents who selected the "Lack of collaboration among peers" as a constraint was greater within the University subsystem. The absolute difference found regarding the "Lack of technological resources" constraint obtained statistical significance $(\chi 2=7.11, \mathrm{p}=<.01)$.

Due to the absence of valid answers from the Polytechnic subsystem of the Madeira AR, this analysis cannot be performed. Nevertheless, it is of interest to look at the main constraint identified by University faculty members, which corresponds to the "Centralized management model of the institution." This constraint was only chosen by University faculty members from the autonomous regions.

Regarding the Azores AR, the proportion of faculty members who selected the "Lack of technological resources" and "Limited infrastructure and resources" options as constraints to digital innovation was higher within the Polytechnic subsystem. Differently, the proportion of respondents who selected the "Centralized management 


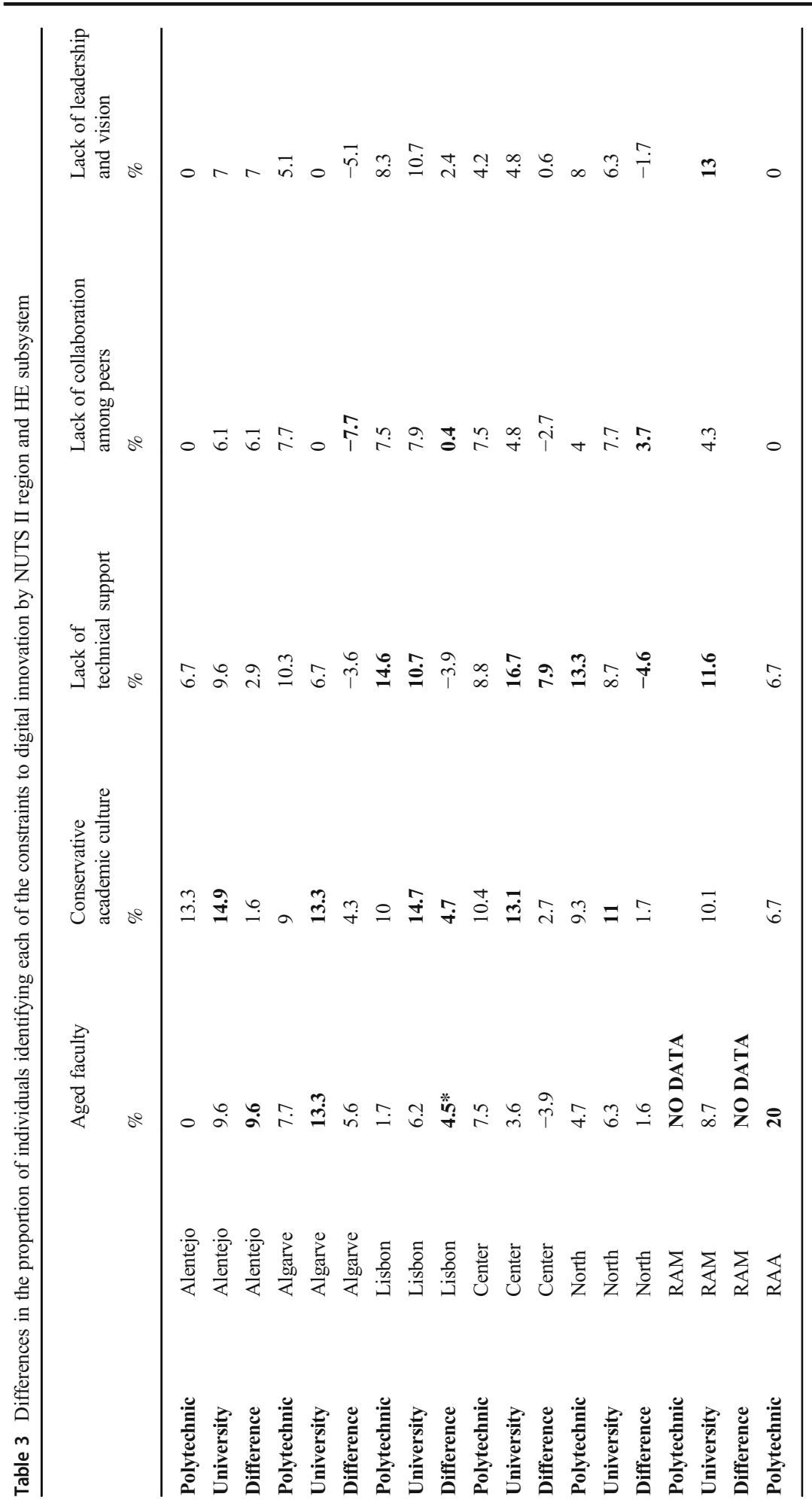




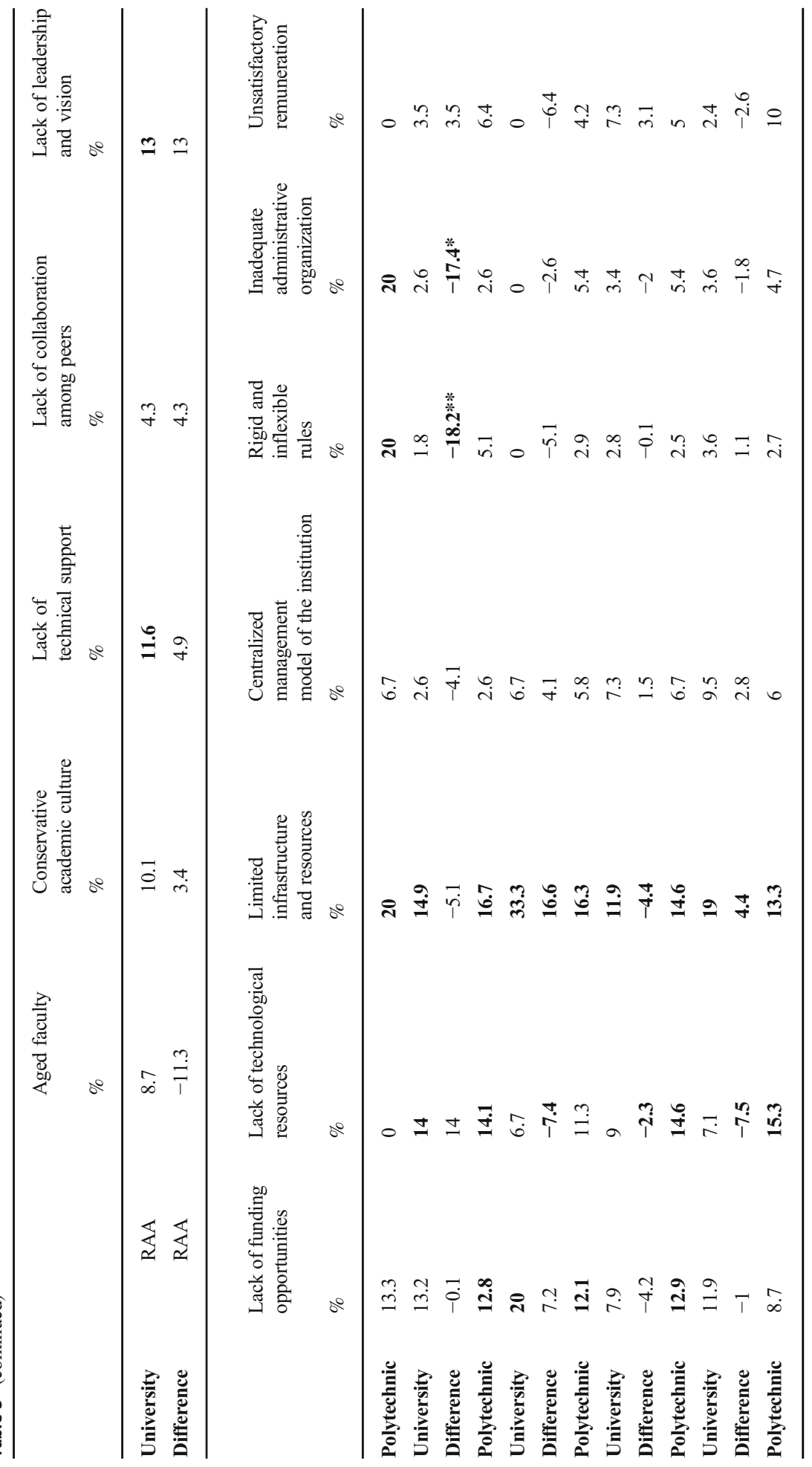




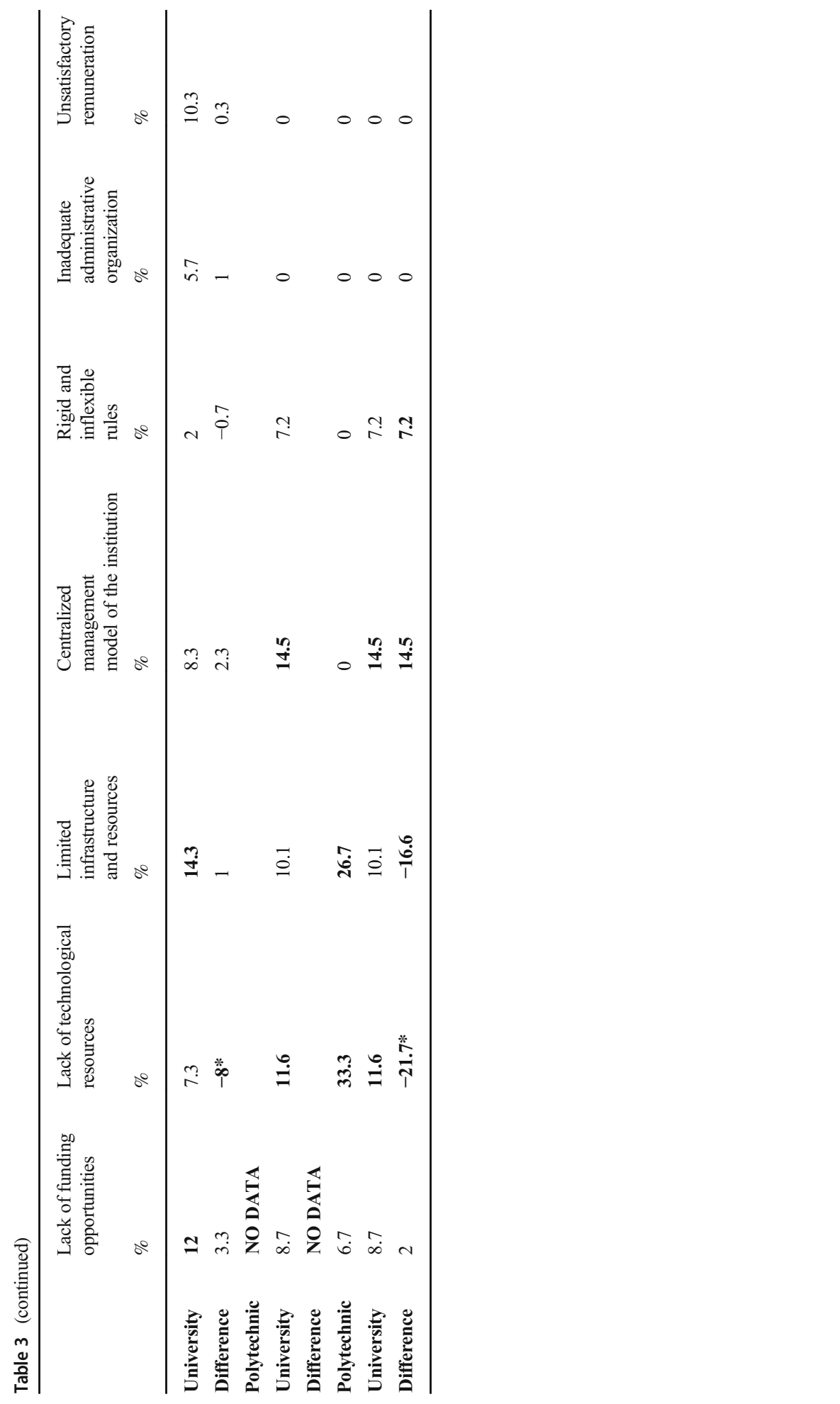


model of the institution" option as a constraint to digital innovation was greater within the University subsystem. The absolute difference found in the "Lack of technological resources" constraint obtained statistical significance $(\chi 2=4.45, p=.035)$.

A global analysis enables us to verify the weight of the constraint "Limited infrastructure and resources." The dominance of this constraint was not found within the University subsystems from the Portuguese autonomous regions. Figure 3 (left panel) identifies the proportion of respondents who reported the five most selected constraints [1 - Limited infrastructure and resources; 2 - Lack of funding opportunities; 3 - Lack of technological resources; 4 - Conservative academic culture; 5 - Lack of technical support].

A chi-square analysis shows a statistically significant difference between the proportion of the first (Limited infrastructure and resources) and the second (Lack of funding opportunities) most reported constraints $(\chi 2=7.3, p<.01$; See difference in Fig. 3, Right Panel).

To complement these results, Fig. 4 provides an overview of the main constraints, which hinder digital innovation. Again, these, independently from NUTS II region or HE subsystem, correspond to Limited infrastructure and resources, Lack of funding opportunities, Lack of technological resources, Conservative academic culture, and Lack of technical support.

\section{Discussion}

The main objective of this study was to characterize the quality of the available digital infrastructure and resources (hardware and software) and to identify the main

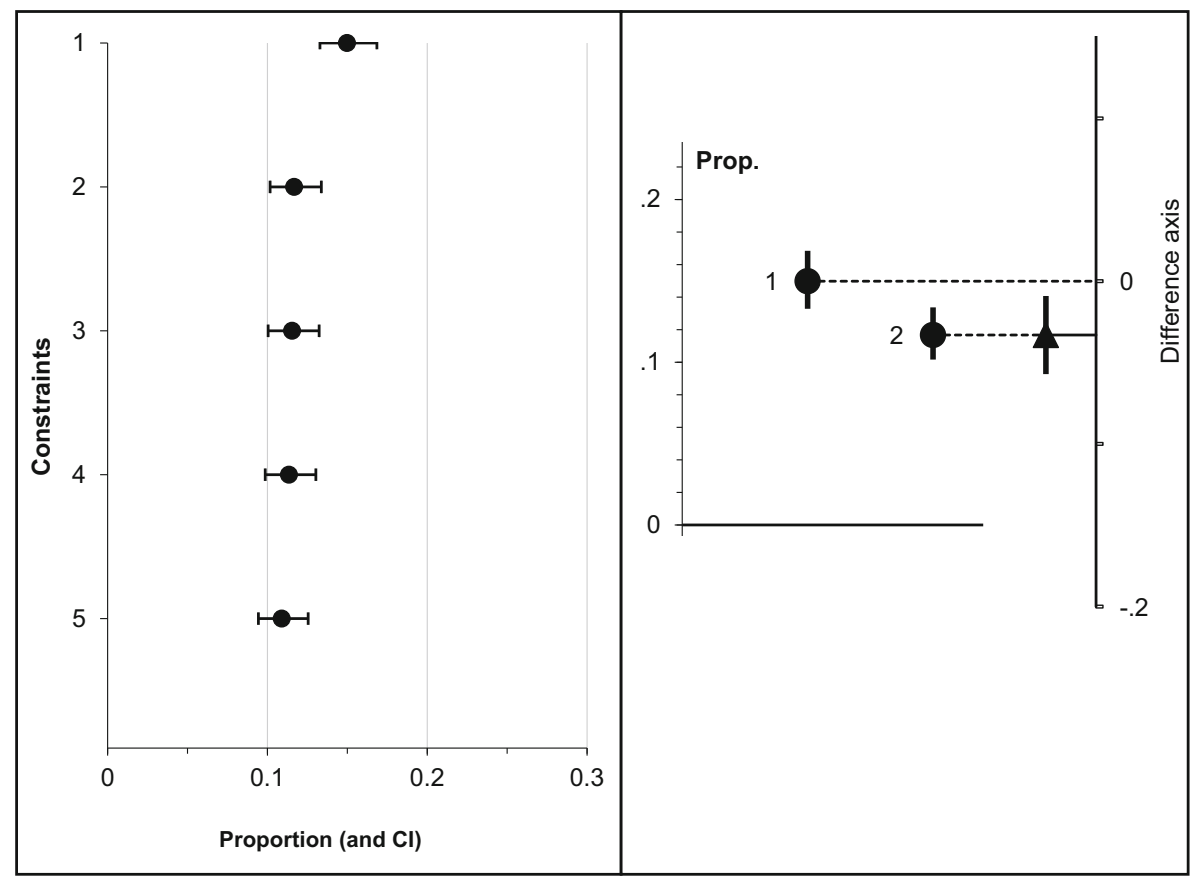

Fig. 3 Proportion of respondents who reported the five most selected constraints 


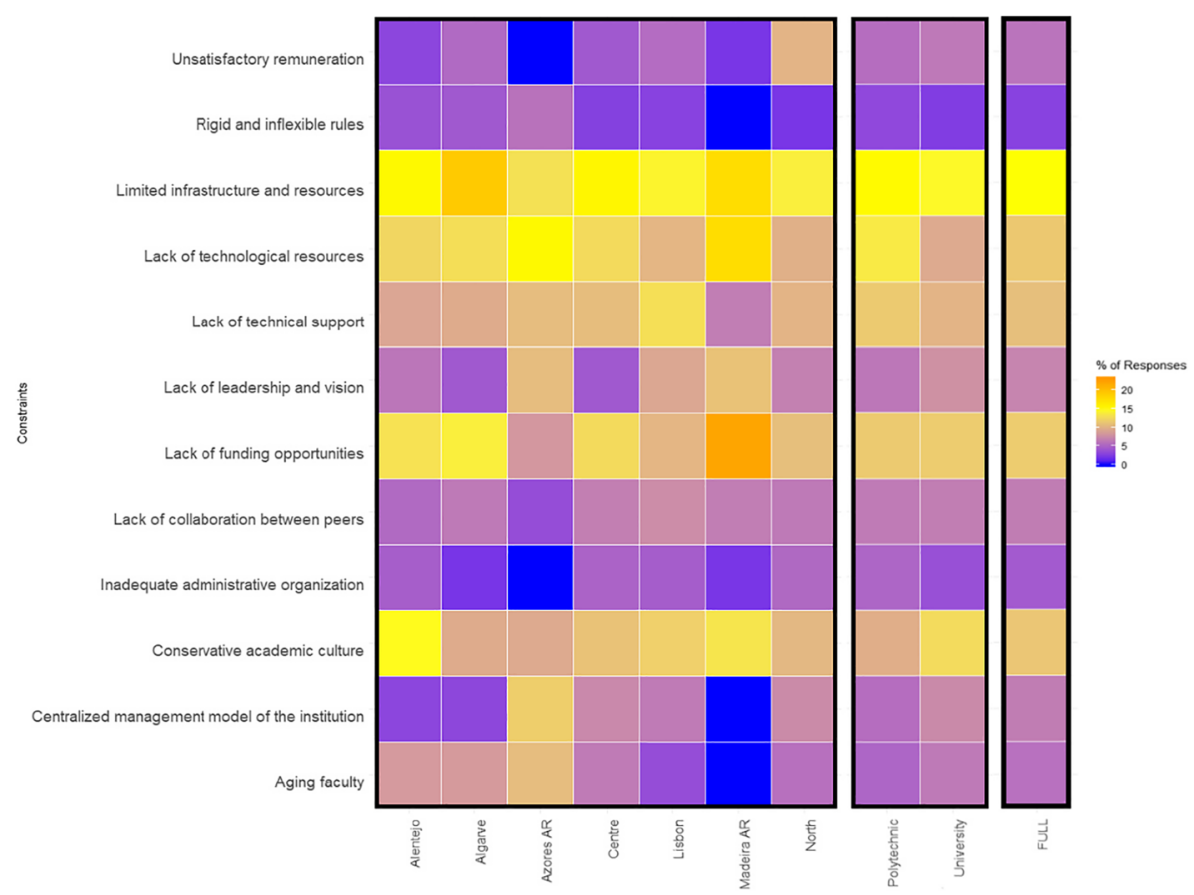

Fig. 4 Response (\%) in each constraint according to NUTS II region, HE subsystem, and full sample

constraints to digital innovation in Portuguese universities and polytechnic institutions. Regarding the quality of the available digital infrastructure, the study results suggest a homogeneity of perceived quality across regions. The exception can be found in relation to the Azores AR, which registers values of perceived quality well below those registered in other regions. This finding may come as no surprise given the RDI (Ferreira and Amaral 2019), which places the Azores AR in the last position of the digital level, despite scoring higher than the national average where infrastructure is concerned. Results are also consistent with the study of Ávila et al. (2017), which points at differences between geographical regions in terms of conditions and constraints faced by HEIs. The same can be said in relation to the perceived quality of the available resources. Again, respondents from the Azores AR have a lower perception of the quality of available hardware and software as compared to other regions. This result recommends carrying out further studies in peripheral regions, particularly in island regions, dedicated to verifying more deeply the correlation between the geographic distance to political decision-making national bodies and the levels of satisfaction of faculty members when regarding the quality of the available digital infrastructure and resources.

Concerning the main constraints to digital innovation, our results are consistent with previous studies (Lašáková et al. 2017; Marshall 2018a, 2018b; Sanderson 2018), having found that the main constraints are (\#1) the limited infrastructure and resources, (\#2) a lack of funding opportunities, (\#3) a lack of technological resources, (\#4) a conservative academic culture, and (\#5) a lack of technical support. Considering that HEIs are expected by policymakers to be key agents for innovation and regional development, our results signal what we call a practical expectation gap, i.e., a significant inconsistency between the general prospect by policymakers that HEIs play 
a leading role in digital innovation, capable of leveraging regional and national development, and the fundamental material conditions needed for that mission to be fully achieved. On the other hand, we consider of particular importance that studies with an ethnographic nature are developed, allowing a deeper qualitative characterization of academic culture, predominantly the innovative/conservative axis in the face of contemporary challenges.

Considering the five main constraints to innovation identified, for the practice of educational policies, there is a clear need for both a national strategic intervention, as well as for local specific planning that addresses the material conditions to support HE societal missions in Portugal. If, on the one hand, Portuguese HEIs are expected to play significant roles in the knowledge society, namely, through innovation, R\&D, and enhanced regional and/or national economic value, on the other, the negative impact unreliable and/or unavailable infrastructures and resources have on the activities of HEI faculty is now solidly documented. Our findings are aligned with previous inquiries across distinct national realities (Ávila et al. 2017; Ferreira and Amaral 2019).

It is striking to notice that infrastructure, technological resources, and technical support are amongst the top barriers to digital innovation in Portuguese universities and polytechnic institutes. The inadequate and/or asymmetric availability of digital infrastructure and resources is hindering the innovative potential of digitization in the Portuguese context. This fact underlines the significant divide, also stressed by the European Commission Digital Education Action Plan (2018), still in place between and within EU member states, regarding digital infrastructure, which hinders inclusive growth. This is a crucial path for future research in this field.

In view of these results, future studies need to appreciate if/how the possible benefits coming from the interconnectedness of academic research and HEIs' economic activity are indeed being retained and reinvested in support of the development of HEIs' innovative potential, as previous research has shown the existence of a positive and significant effect of business, public, and HE R\&D on innovation in the EU (Pegkas et al. 2019) and, particularly, that science-based and knowledge-intensive business services are active collaborators with universities for innovation (Lee and Miozzo 2019). In the Portuguese context, it is still unclear if/how HEIs are sharing knowledge and technological assets across organizational boundaries.

On the other hand, considering the reported relationship between HEIs and regional economic impact (Brennan et al. 2018; Caniëls and van den Bosch 2010; Valero and Reenen 2019), a new branch of studies also needs to address the real contribution of regionally based policy making on digital innovation and assess its efficiency on closing the asymmetries between high and low and between coastal and interior regional economies. Complementarily, both from a research and a scientific policy-making perspective, studies on the drivers of and barriers to collaboration between Portuguese universities and polytechnic institutes are lacking. In particular, the flow level of shared knowledge, technical expertise, and technological infrastructure must be evaluated toward the possible creation of joint ventures and regional I\&D clusters among HEIs.

\subsection{Study limitations}

Despite comprising the most comprehensive online questionnaire available to date on digital innovation in Portuguese HEIs, our study has some limitations: (1) its 
exploratory nature led us to choose a quantitative research design operationalized through an online questionnaire aimed at covering both Portuguese universities and polytechnic institutes across the public and the private sectors and in all scientific domains and regions. Quantitative data generated by our online questionnaire was analyzed descriptively, asking for further cross-variate analysis work. Without a complementary qualitative research approach (e.g., semi-structured interviews), the reading of the data we generated will remain incomplete. (2) Considering the purposive sample database of 8563 entries, the response rate is low (6.4\%). Respondents who answered the questionnaire did so voluntarily, which may have led to a selection bias in favor of those participating who are already interested in digital innovation. (3) Because a webbased questionnaire was used to gather the data, this may have led to faculty members already feeling some degree of engagement with digital technologies being the ones willing to participate in our study. (4) Despite conducting the most comprehensive online questionnaire on digital innovation in Portuguese HEIs to date $(N=547)$, no statistical representativeness is claimed. A generalization of the results across sociodemographic variables must be appreciated with particular epistemological moderation and considered in future developments, as sampling, due to its exploratory design, may affect generalizability and, particularly, underrepresentation.

\section{References}

Altbach, P. G. (2016). Global perspectives on higher education. Baltimore: Johns Hopkins University Press.

Alves, J., Carvalho, L., Carvalho, R., Correia, F., Cunha, J., Farinha, L., et al. (2015). The impact of polytechnic institutes on the local economy. Tertiary Education and Management, 21(2), 81-98. https://doi.org/10.1080/13583883.2014.999110.

Ávila, L. V., Filho, W. L., Brandli, L., Macgregor, C. J., Molthan-Hill, P., Özuyar, P. G., \& Moreira, R. M. (2017). Barriers to innovation and sustainability at universities around the world. Journal of Cleaner Production, 164, 1268-1278. https://doi.org/10.1016/j.jclepro.2017.07.025.

Blaschke, S., Frost, J., \& Hattke, F. (2014). Towards a micro foundation of leadership, governance, and management in universities. Higher Education, 68, 711-732. https://doi.org/10.1007/s10734-014-9740-2.

Bond, M., Marín, V. I., Dolch, C., Bedenlier, S., \& Zawacki-Richter, O. (2018). Digital transformation in German higher education: Student and teacher perceptions and usage of digital media. International Journal of Educational Technology in Higher Education, 15(48). https://doi.org/10.1186/s41239-0180130-1.

Brennan, J., Broek, S., Durazzi, N., Kamphuis, B., Ranga, M., \& Ryan, S. (2014). Study on innovation in higher education: final report. European Commission Directorate for education and training study on innovation in higher education. Luxembourg: Publications Office of the European Union.

Brennan, J., Cochrane, A. C., Lebeau, Y., \& Williams, R. K. (2018). The university in its place: Social and cultural perspectives on the regional role of universities. Dortrecht: Springer.

Caniëls, M., \& van den Bosch, H. (2010). The role of higher education institutions in building regional innovation systems. Papers in Regional Science, 90(2), 271-287. https://doi.org/10.1111/j.14355957.2010.00344.x.

Commission, European. 2018. COM(2018)22 final on the Digital Education Action Plan. In. Brussels: European Comission. https://eur-lex.europa.eu/legal-content/EN/TXT/?uri=COM:2018:22:FIN

Dias, A., \& Gomes, M. J. (2018). A wake-up call for B-learning in Portuguese higher education. In Chova et al. (Eds.), 10th International Conference on Education and New Learning Technologies: EDULEARN18 (pp. 7944-7954). IATED Academy.

Direção Geral do Ensino Superior (DGES). (2017). Study \& research in Portugal. https://www.studyresearch.pt/en/dashboard/. Accessed March 232020.

Direção Geral do Ensino Superior (DGES). (2018). Higher education research and innovation in Portugal: Perspectives for 2030. Lisboa: DGES https://www.dges.gov.pt/sites/default/files/portugal_teri_system_ rev_v14fev2018_v3_com_capa-compressed.pdf. Accessed March 232020. 
European Commission (2014). Higher education institutions (HEIs) as centers of regional development and innovation: ET 2020 working group on modernisation of higher education. https://ec.europa. $\mathrm{eu} /$ transparency/regexpert/index.cfm?do=groupDetail.groupDetailDoc\&id=28229\&no=5. Accessed March 232020.

European Commission. (2018). Communication from the commission to the European Parliament, the council, the European economic and social committee, and the Committee of the Regions on the digital education action plan: $\operatorname{COM}(2018) 22$ final. Brussels: European Commission.

European Higher Education Area (EHAE). (1999). The Bologna Declaration of 19 June 1999. http://www. magna-charta.org/resources/files/text-of-the-bologna-declaration. Accessed March 232020.

Fernandes, J., Cunha, J., \& Oliveira, P. (2013). The socioeconomic impact of an HEI for a local economy. In B. Boufoy-Bastick (Ed.), The international handbook of cultures of education policy (Vol. 1, pp. 557575). Strasbourg: Analytics.

Ferreira, L. M., \& Amaral, L. (2019). Índice Digital Regional 2018 [Regional Digital Index 2018]. GáveaObservatório da Sociedade da Informação. Guimarães: Universidade do Minho.

Figueiredo, H., Biscaia, R., Rocha, V., \& Teixeira, P. (2017). Should we start worrying? Mass higher education, skill demand and the increasingly complex landscape of young graduates' employment. Studies in Higher Education, 42(8), 1401-1420. https://doi.org/10.1080/03075079.2015.1101754.

File, J. (2008). Higher education in Portugal: IHEM country report. Enschede: Center for Higher Education Policy Studies.

Flores, M. A., Brown, G., Pereira, D., Coutinho, C., Santos, P., \& Pinheiro, C. (2019). Portuguese university students' conceptions of assessment: Taking responsibility for achievement. Higher Education, 79, 377394. https://doi.org/10.1007/s10734-019-00415-2.

Fox, R. (2011). Technological practice and change in education. In R. Kwan et al. (Eds.), enhancing learning through technology. education unplugged: Mobile technologies and Web 2.0. ICT 2011. Communications in computer and information science (Vol. 177, pp. 1-7). Berlin, Heidelberg: Springer. https://doi. org/10.1007/978-3-642-22383-9_1.

García, L. M., \& Roblin, N. P. (2008). Innovation, research, and professional development in higher education: Learning from our own experience. Teaching and Teacher Education, 24(1), 104-116. https://doi.org/10.1016/j.tate.2007.03.007.

Governo da República Portuguesa. (2017). Programa nacional para a coesão territorial [National program for territorial cohesion]. https://www.portugal.gov.pt/pt/gc21/governo/programa/programa-nacionalpara-a-coesao-territorial-/ficheiros-coesao-territorial/programa-nacional-para-a-coesao-territorial-pdf.aspx

Harrison, H. D., \& Hargrove, M. J. (2006). Aging faculty: Workforce challenges and issues facing higher education. Business Perspectives, 18(2), 20-25.

Hasanefendic, S., Birkholz, J. M., Horta, H., \& van der Sijde, P. (2017). Individuals in action: Bringing about innovation in higher education. European Journal of Higher Education, 7(2), 101-119. https://doi. org/10.1080/21568235.2017.1296367.

Kauko, J., \& Diogo, S. (2012). Comparing higher education reforms in Finland and Portugal. Higher Education Management and Policy, 23(3), 1-20. https://doi.org/10.1787/17269822.

Kezar, A. J. (2018). Asset-based or burden-based views of senior and retired faculty: How values translate into culture and shape practice and policies. New Directions for Higher Education, 182, 57-67. https://doi. org/10.1002/he.20280.

Kezar, A. J., \& Eckel, P. D. (2002). The effect of institutional culture on change strategies in higher education: Universal principles or culturally responsive concepts? The Journal of Higher Education, 73(4), 435-460. https://doi.org/10.1080/00221546.2002.11777159.

Kraft, R. H. P. (1971). Technological change and educational obsolescence: Challenges to administrators as managers of change. International Review of Education, 17(3), 309-323. https://doi.org/10.1007 /BF01421380.

Lašáková, A., Bajzíková, L., \& Dedze, I. (2017). Barriers and drivers of innovation in higher education: Case study-based evidence across ten European universities. International Journal of Educational Development, 55, 69-79. https://doi.org/10.1016/j.ijedudev.2017.06.002.

Lee, H.-F., \& Miozzo, M. (2019). Which types of knowledge-intensive business services firms collaborate with universities for innovation? Research Policy, 48(7), 1633-1646. https://doi.org/10.1016/j. respol.2019.03.014.

Luehrmann, A. (1989). Technological innovations in higher education: Are they possible? Journal of Computing in Higher Education, 1(1), 117-127. https://doi.org/10.1007/BF02942609.

Marshall, S. J. (2018a). Financial challenges, constraints, and consequences of funding higher education. In S. J. Marshall (Ed.), Shaping the university of the future (pp. 103-121). Singapore: Springer. https://doi. org/10.1007/978-981-10-7620-6_5. 
Marshall, S. J. (2018b). Technology as a catalyst for change. In S. J. Marshall (Ed.), Shaping the University of the Future (pp. 147-166). Singapore: Springer. https://doi.org/10.1007/978-981-10-7620-6_8.

Mesquita, A., \& Castilho, O. (2017). Enablers and constrainers of internationalization of higher education institutions: A case study from Portugal. In R. L. Raby \& E. J. Valeau (Eds.), Handbook of comparative studies on community colleges and global counterparts (pp. 1-26). Cham: Springer. https://doi. org/10.1007/978-3-319-38909-7_17-1.

Moodie, G. (2016). Universities, disruptive technologies, and continuity in higher education: The impact of information revolutions. New York: Palgrave Macmillan US.

OECD. (2019). OECD review of higher education, research, and innovation: Portugal. https://oi. org/10.1787/9789264308138-en.

Paganelli, A., \& Cangemi, J. (2019). Effects of aging faculty. Education, 139(3), 151-157.

Pegkas, P., Staikouras, C., \& Tsamadias, C. (2019). Does research and development expenditure impact innovation? Evidence from the European Union countries. Journal of Policy Modeling, 41, 1005-1025. https://doi.org/10.1016/j.jpolmod.2019.07.001.

PORDATA. (2019). Institutions in higher education: total and by type of education. https://www.pordata. $\mathrm{pt} / \mathrm{en} /$ Municipalities/Institutions+in+higher+education+total+and+by+type+of+education-336

Posselt, T., Abdelkafi, N., Fischer, L., \& Tangour, C. (2018). Opportunities and challenges of higher education institutions in Europe: An analysis from a business model perspective. Higher Education Quarterly, 73(1), 100-115. https://doi.org/10.1111/hequ.12192.

Rampelt, F., Suter, R., Orr, D., Hijden, P., \& Röwert, R. (2018). Bologna Digital position paper. Berlin: Kiron Open Higher Education https://kiron.ngo/2018/03/27/bolognadigital/.

Razik, T. A., \& Nalbone, P. J. (1990). Implications of technological change for higher education reform. Educational Technology Research and Development, 38(1), 65-76. https://doi.org/10.1007/BF02298249.

Reichert, S. (2019). The role of universities in regional innovation ecosystems. Brussels. European University Association. https://eua.eu/resources/publications/819:the-role-of-universities-in-regional-innovationecosystems.html

Rosario, M. D. (2012). ICT in education policies and national development. In R. Clothey, S. Austin-Li, \& J. C. Weidman (Eds.), Post-secondary education and technology: A global perspective on opportunities and obstacles to development (pp. 17-38). New York: Palgrave Macmillan US.

Sanderson, R. (2018). When is a leader not a leader? Experiences of programme leadership in a post-92 University. IMPact: The University of Lincoln Journal of Higher Education Research, 1(1). https://doi. org/10.25507/1120189.

Serdyukov, P. (2017). Innovation in education: What works, what doesn't, and what to do about it? Journal of Research in Innovative Teaching \& Learning, 10(1), 4-33.

Shoham, S., \& Perry, M. (2009). Knowledge management as a mechanism for technological and organizational change management in Israeli universities. Higher Education, 57(2), 227-246. https://doi. org/10.1007/s10734-008-9148-y.

Smertenko, P., Dimitriev, O., Pochekailova, L., \& Cernyshov, L. (2018). Technological transformations and their implications for higher education. In J. Valsiner, A. Lutsenko, \& A. Antoniouk (Eds.), Sustainable futures for higher education: The making of knowledge makers (pp. 67-75). Cham: Springer International Publishing.

Valero, A., \& Reenen, J. V. (2019). The economic impact of universities: Evidence from across the globe. Economics of Education Review, 68, 53-67. https://doi.org/10.1016/j.econedurev.2018.09.001.

Välimaa, J., \& Hoffman, D. (2008). Knowledge society discourse and higher education. Higher Education, 56(3), 265-285. https://doi.org/10.1007/s10734-008-9123-7.

Veletsianos, G. (Ed.). (2016). Emergence and innovation in digital learning. Edmonton: Athabasca University Press.

Publisher's note Springer Nature remains neutral with regard to jurisdictional claims in published maps and institutional affiliations. 